\title{
Ryan Blue Staining Method
}

National Cancer Institute

\section{Source}

National Cancer Institute. Ryan Blue Staining Method. NCI Thesaurus. Code C85801.

A microscopy staining method that utilizes a modified trichrome stain to determine the presence of microsporidial species. This staining technique substitutes aniline blue for the fast green counterstain of the orig inal trichrome staining method and decreased levels of phosphotungstic acid in the reagent. 